\title{
Software toolchain to enhance the management and integration of a sustainable campus model
}

\author{
Luiz C. P. da Silva' ${ }^{1}$, Paulo C. M. Meira', João G. I. Cypriano ${ }^{1}$, Hader A. D. Azzini ${ }^{1}$ and Athila Q. Santos ${ }^{2 *}$ \\ From 1st Energy Informatics. Academy Conference Asia \\ Beijing, China. 29-30 May 2021
}

\author{
*Correspondence: aqs@mmmi.sdu. \\ dk \\ ${ }^{2}$ Center for Energy Informatics, \\ University of Southern Denmark, \\ Mærsk Mc-Kinney Møller Instituttet, \\ Odense, Denmark \\ Full list of author information is \\ available at the end of the article
}

\begin{abstract}
The aim of this article is to describe a novel ICT-centred methodology and software toolchain to enhance the management of a Smart Campus. The project will be implemented at the University of Campinas through a partnership between UNICAMP, CPFL (local Utility Distribution Company) and the University of Southern Denmark. This project was recently submitted to a strategic and priority call from the Brazilian Regulatory Agency (National Electric Energy Agency - ANEEL, acronym in Portuguese). The project integrates energy efficiency with research and development in distributed generation with an innovative loT-based DMS energy management tool. These actions comply with the ISCN/GULF Sustainable Campus Chapter policies, signed by UNICAMP a few years ago. This paper is important because it will result in a replicable model for sustainable campuses, with a detailed step-by-step procedure covering local mini-grid EMS, IOT DMS, Mobility, real-time retrofitted efficiency and institutional energy governance.
\end{abstract}

Keywords: Energy efficiency, Sustainability, Sustainable campus, Software toolchain

\section{Introduction}

One of the main challenges of today's society is the reduction of energy consumption and, consequently, the greenhouse gas emissions. Using 2005 levels as the baseline, Brazil committed to cutting emissions $37 \%$ by 2025 , with a subsequent reduction of $43 \%$ by 2030 , according to the Paris agreement (Government, 2016). In addition, building installations account for approximately $40 \%$ of global energy consumption and about 36\% of total $\mathrm{CO} 2$ emissions (Facts\&Trends: Energy efficiency in buildings, 2008). Therefore, the development of sustainable alternatives in the management and control of energy systems is an indispensable factor in achieving such goals.

For this purpose, it is essential to analyze the flexibility provided by Renewable Energy Sources (RES), Distributed Energy Resources (DER) and Microgrids in order to efficiently use the existing resources and the infrastructures present in the network and

(c) The Author(s). 2021 Open Access This article is licensed under a Creative Commons Attribution 4.0 International License, which permits use, sharing, adaptation, distribution and reproduction in any medium or format, as long as you give appropriate credit to the original author(s) and the source, provide a link to the Creative Commons licence, and indicate if changes were made. The images or other third party material in this article are included in the article's Creative Commons licence, unless indicated otherwise in a credit line to the material. If material is not included in the article's Creative Commons licence and your intended use is not permitted by statutory regulation or exceeds the permitted use, you will need to obtain permission directly from the copyright holder. To view a copy of this licence, visit http://creativecommons.org/licenses/by/4.0/. 
to validate adequate management systems. Smart Campus case studies can provide small scale pilot projects to implement proposal ideas and define suitable control schemes to be integrated into the main grid (Bracco et al., 2017).

Smart Campus must unleash management opportunities and take advantage of the monitoring and control infrastructure. To accomplish that, an ICT-centred methodology and software toolchain not only should improve the overall energy consumption, but also offer public authorities, utilities and decision makers dedicated tools to plan strategies (Aghemo et al., 2013). For management to be successful, the state-of-art in Energy Management System (EMS) needs to be advanced to improve energy performance of the whole campus ecosystem (Aghemo et al., 2013). The efficient management of Smart Campus is even more challenging when considering that this kind of application has complex occupant behaviour, integrated energy systems and interactions among their subsystems (Delzendeh et al., 2017; Yousefi et al., 2017; Quan et al., 2014).

Furthermore, electric energy consumption in Brazilian Federal Universities is the third largest expense for these institutions on a yearly basis (ANEEL, 2017), most of which is used for air conditioning. Therefore, the development of an energy monitoring and building management systems using Internet of Things (IoT) infrastructure for a smart campus represents an important pilot project to explore opportunities and challenges in the smart cities and efficient buildings field.

In addition, since April 2015, University of Campinas (UNICAMP) signed the Sustainable Campus Charter Program (ISCN-GULF) for the exchange of information, ideas and practical improvements in sustainable operations. This project integrates sustainability in research and teaching, counting on members such as Harvard University, the Massachusetts Institute of Technology (MIT) and Yale University. This partnership has the objective of planning, developing, training and managing actions, projects and institutional programs related to sustainability, based on continuous improvement and environmental, economic and social performance.

Technical and scientific literature associated with other studies and applications shows that it is possible to use advanced computational tools using an appropriate set of technologies and services over the internet, such as IoT services, Big Data (Wan et al., 2017), Mobile Connection (Zhang et al., 2012), Machine Learning (Polyzotis et al., 2017), Multi-Agent System (MAS) (Jennings \& Wooldridge, 1995; Ferber et al., 2004) and Cloud Computing (Sun et al., 2016; Wang et al., 2017) to integrate isolated systems and optimize the management and control processes, replacing the past static model and adding intelligent features. The distributed characteristic of the sensors and the communication capability of the environment make possible the use of cloud computing to process all the controller's adjustment in real-time and to calculate the overall optimization of the system.

The world is progressively becoming reliant on digital services, increasing the demand for processing, data transmission and storage. Web-based applications, social, and multimedia resources enhanced by the mobile and wireless networks are the driving forces for cloud computing infrastructure investments and the advent of the IoT. As a natural consequence, energy systems are gradually moving towards modernization that increases improvements in their performance. It is essential the automation of new and existing processes using state-of-the-art in remote sensing operations, communication, control and information technology. The purpose is to meet intelligent integration 
to the actions of all its elements in order to provide sustainable, economic and secure energy supply.

The software platform is part of the Smart Campus initiative to transform the UNICAMP into a campus-scale "living laboratory" for promoting energy savings and environmental sustainability. The project will provide the theoretical and technical foundation needed to develop, implement, and evaluate an integrated software toolchain methodology that can generate valuable information for efficient management of Smart Campus. Specifically, the project will support decision-makers in the areas of energy-efficiency design, operation management and intelligent services.

\section{Purpose}

This project aims to develop a complete software toolchain to enhance the management and integration of a sustainable campus model. Improving such control can increase efficiency, reduce waste and energy use, and lower greenhouse gas emissions from public services and infrastructures (Bates \& Friday, 2017). The novel ICT-centred methodology and software toolchain will enhance the management of Smart Campus and offer to public authorities and decision makers dedicated tools to plan strategies for more complex systems. To achieve its overall aim the following specific technical objectives should be accomplished:

- An online energy performance monitoring, simulation and evaluation tool for individual buildings and blocks of buildings under real operation conditions, considering important factors including occupancy and user behaviour, physical envelope, energy systems operation, and weather forecast, to ensure that buildings are operated in a way that meets their original design intent;

- An intelligent energy-management system for real-time optimization of energy supply and distribution systems that reduces energy consumption in buildings and blocks of buildings to a value consistent with energy efficiency and performance standards;

The proposed methodology takes a holistic life cycle approach on energy performance, which integrates commissioning, occupancy and user behaviour, physical envelope, energy systems and weather forecast. It also combines energy performance assessment and diagnostics, real-time energy demand and supply optimization, digital building decision support, and a fully integrated chain of software and hardware tools. An unprecedented effort in the Brazilian and international context.

\section{Project description}

The UNICAMP campus is currently implementing an integrated sustainable Living Lab for renewable generation, electric mobility, energy efficiency in buildings, monitoring and energy demand management, as shown by Fig. 1. The project includes 300 measurement points for a Smart Operation Center to improve energy management, including a centralized data base for all systems, monitoring screens, performance index, etc. Additionally, $600 \mathrm{~kW}$ PV microgeneration with various generation plants will be installed in some of the buildings and controlled by an innovative IoT-based distributed management system tool. The project also contemplates electric mobility by electric 


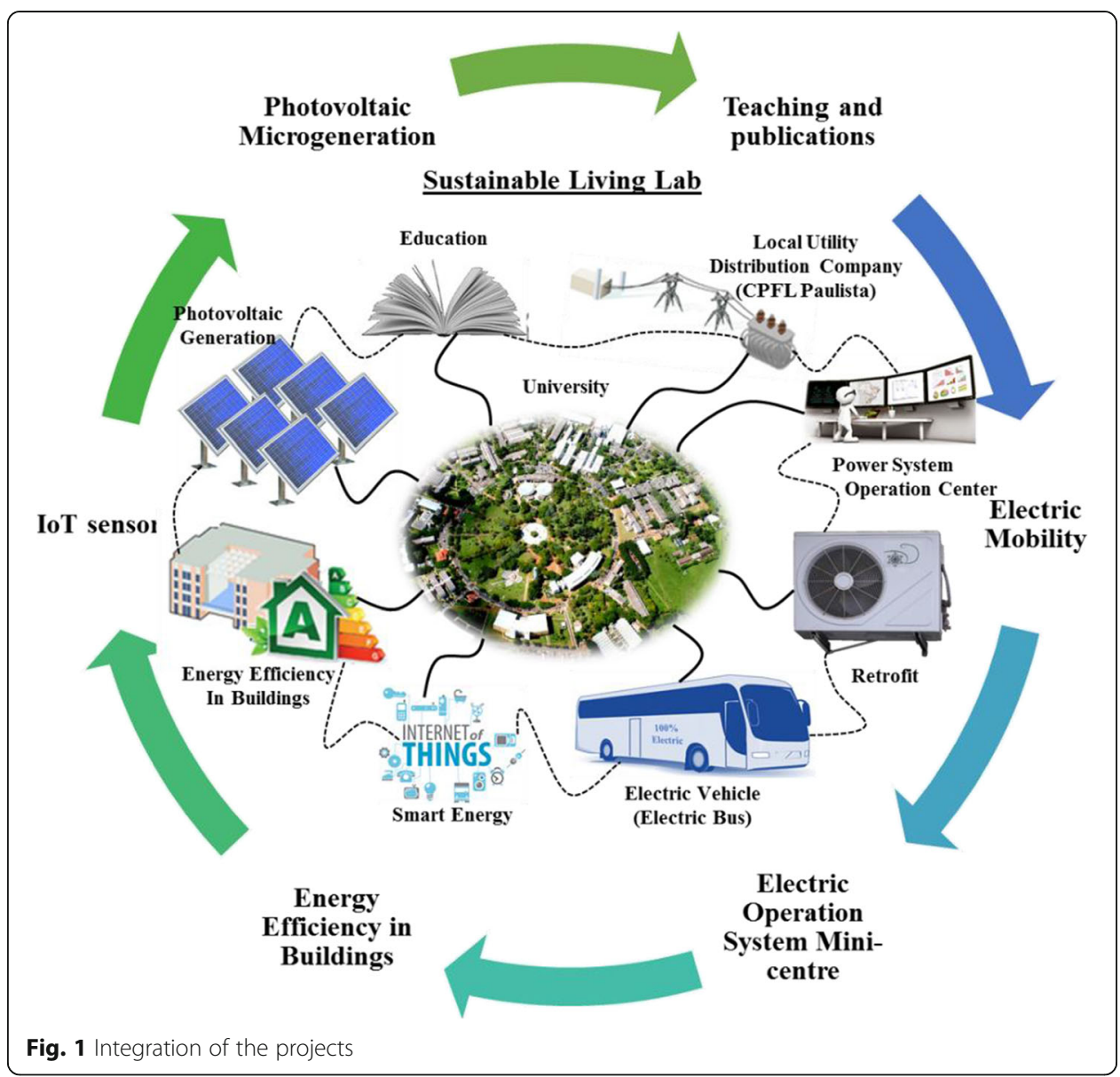

bus, mapping the socio-environmental impacts of using this technology; retrofit and sensors for energy efficiency; and energy monitoring and network evaluation.

It is widely known that power consumption without monitoring and financial accountability is the greatest incentive for inefficiency and irrational use of electricity. Therefore, in order to fulfill the goals towards developing a Sustainable Campus, it is a priority for the university to build a data centre for measuring consumption. It should also take advantage of this opportunity to build a hardware and software infrastructure that can use network analysis and optimization tools, aiming at efficiency gains both from the consumption point of view, as well as the most suitable operation, planning and maintenance of the electrical grid.

Any energy efficiency project depends on sound information to succeed. Implementing this project will continuously and permanently provide information in real time on the energy consumption of the Campus. This project is vitally important for all initiatives to be implemented at the university in the area of energy efficiency and energy conservation. It will also be a living lab to develop research on the topic of power system operation centres.

The experiences from conducting the pilot case studies will facilitate better businessoriented digitalization in public administration and the exploitation of the project's results for public buildings such as schools, administrative and governmental buildings. The sustainable digital infrastructure will provide new innovative commercial products 
and services that will open up new global market opportunities, whereby increasing the global competitiveness of the industry partners. The project will provide the theoretical and technical foundation needed to develop, implement, and evaluate an integrated methodology supported by a set of software tools that can generate valuable information for efficient management of buildings' portfolio. Specifically, the project will support decision-makers in the areas of energy-efficient building design, operation management and retrofits.

\section{Software architecture}

The software architecture aims to implement a smart mini-centre for data consumption and power system operations for the main UNICAMP campus by installing electronic meters in all the consumer units (faculties, institutes, laboratories, interdisciplinary centres, administration, etc.) to monitor the actual consumption of each consumer. Currently, the university is a free consumer and only has the interface measurement with the network of the utility, and therefore does not have much knowledge about the internal losses of its distribution network. Figure 2 shows the relationship between the different hardware and software components and the necessary communication infrastructure.

The project will produce a high volume of data with distinct characteristics. Integration of new equipment data and legacy systems will be performed, leading to an extensive data category list:

- tracking of various time-series, including real-time measurements throughout the campus and performance metrics of various entities:

- electric consumption meters

- water consumption meters

- photovoltaic generators

- weather stations

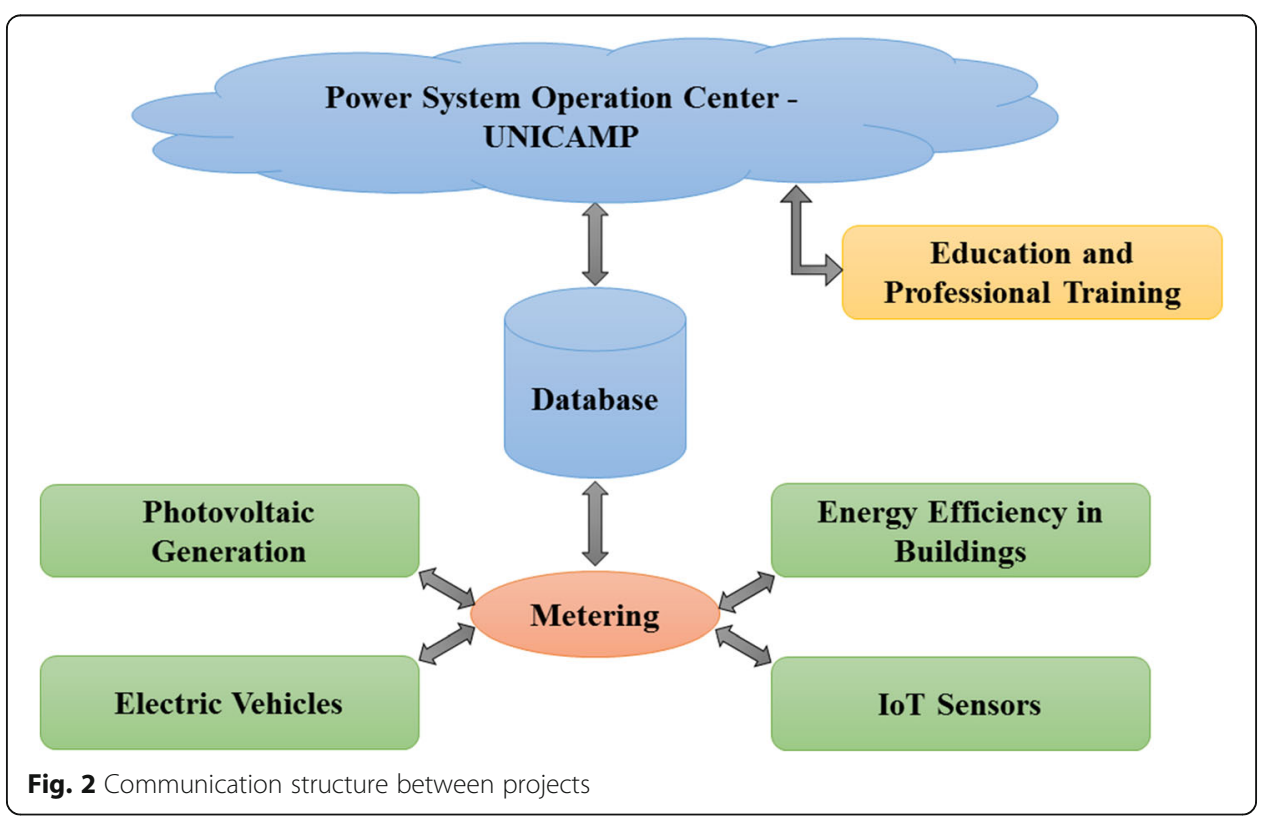


- general distributed IoT sensors

- electric buses and other vehicles, including real-time tracking

- GIS data and electrical parameters of the internal electric network

- general GIS data, such as ways, points of interest and building information

- general asset tracking

- detailed models according to the target studies

- simulation parameters and results

This list of items is comparable to that of a small utility, with the caveat that many aspects will include real-time data. It becomes apparent that mature and reliable database technologies, able to be integrated with modern real-time visualization software and processing for IoT events, are fundamental.

\section{Database architecture}

Since the database is one of the central aspects of the system and it must be able to manage many aspects of the campus data, a good database system and design are essential for reach the goals of the project. Even though there is no expectation of migrating all legacy systems to the proposed solution, there is an effort to at least provide uniform access to legacy data.

The initial prototype will be based on the open-source RDBMS PostgreSQL (or simply Postgres). Postgres uses mature and reliable technology and, even though the initial management will be done by the project's team, there are many companies that provide commercial support, which could be important in the long term for stable operation of the system.

The team plans to integrate many Postgres extensions such as PostGIS, for general GIS functions, and TimescaleDB, for tracking time-series with better performance and resource utilization. Postgres can also interface other database systems and file formats through the concept of Foreign Data Wrappers (FDWs). FDWs are available for many other SQL databases, NoSQL databases, as well as Hadoop and related technologies.

These characteristics enable the creation of a coherent system through the many different domains, ranging from recent real-time data to archived history in the long term. Some data, such as the internal ways and streets of the campus, will be shared directly in the OpenStreetMap (OSM) project. Even before the implementation of the project, many fixes were already made to the OSM data in order to evaluate the possible integration, which seems likely. The OpenStreetMap project itself uses Postgres, although its schema is loose, with tags being represented using key-value pairs. Although the focus and most of the data represents roadways, many other entities with GIS data, such as transmission lines, also include basic representations. Building footprints are present in many regions, with a large (almost ten million high quality building footprints from the USA) being contributed to the project by Microsoft in 2018. All the data, coupled with the emergence of indoor mapping, and a shared goal of open data and public participation, suggest engaging the local OSM community of the campus and its surroundings.

\section{General development}

The backend of the system will be highly based on the database and communication with meters and other devices, the initial and most accessible interface to the system 
will be based on web technologies, running in modern web browsers. While the initial development is carried in a couple of physical server-grade machines, managed directly by the development team, the software solutions can be integrated to the university's cloud initiative. Using this cloud infrastructure would allow on demand studies and dynamical scaling of usage of resources shared with the university community.

As the project explores various areas of expertise and each of those has expectations about presentation and terminology, instead of developing a monolithic application, the system will be structured from individual compose building blocks. They will be based on modules for general data-management, user interfaces and GIS tools. Integration with existing desktop software and services is also envisioned as the system matures. The integration includes direct plugins or standalone importer-exporters for existing GIS software (such as QGIS), OpenStudio (whole building modelling) and data science tools.

Since different users may run different profiles of studies and analysis, it will also be important to allow exporting subsets of the whole data respecting selected profiles, either for the analysis integrated into the system or for offline usage. Existing technologies such as Dojot (CPQD, 2017) may ease the implementation of such selective data sets in the final system. To facilitate the community involvement in the developing unique and innovative of IoT interaction modules, current frontend and API standards will be evaluated and implemented.

\section{Methodology}

The implementation was divided into three phases: 1) Installation, 2) Operation and 3) Internalization. The installation phase comprises the period of installation and maturity of the adopted solutions, so that the systems of each technology supplier are used. In the case of smart electricity meters, the company itself (Time Energy) provides the data collected daily together with its own management and visualization platform. The same occurs with the photovoltaic system. In addition, in this period the analysis and testing of communication solutions take place. The main communication technology is the WiFi network, in which specific channels for IoT solutions were replicated throughout the university campus, together with the expansion of the network by using access points. For "dark" regions, two technologies for IoT data communication are being tested and evaluated, which are: LoRa Wan and RF-Mesh. Figure 3 shows the coverage of the three network types.

In the operation phase, after the stability of the installed systems, the period of data collection and validation begins, so that commercial solutions for data management and visualization become secondary and a university specific system becomes a priority, according to the real need of the institution, researchers and managers. As it is a multifunction, research and administrative platform, its implementation must be accompanied by both agents. We will use the Dojot solution (CPqD) as a middleware, between sensors/collectors and database. This platform also allows the creation of dashboards and APIs for accessing data, as well as a web interface. The internalization phase is when the project is completed and its results are incorporated into the organizational and physical structure of the University. Moving on to internal management and the open use of the platform, i.e., the administrative bodies of the University that will be responsible for the installation, expansion, maintenance and operation of these systems. 


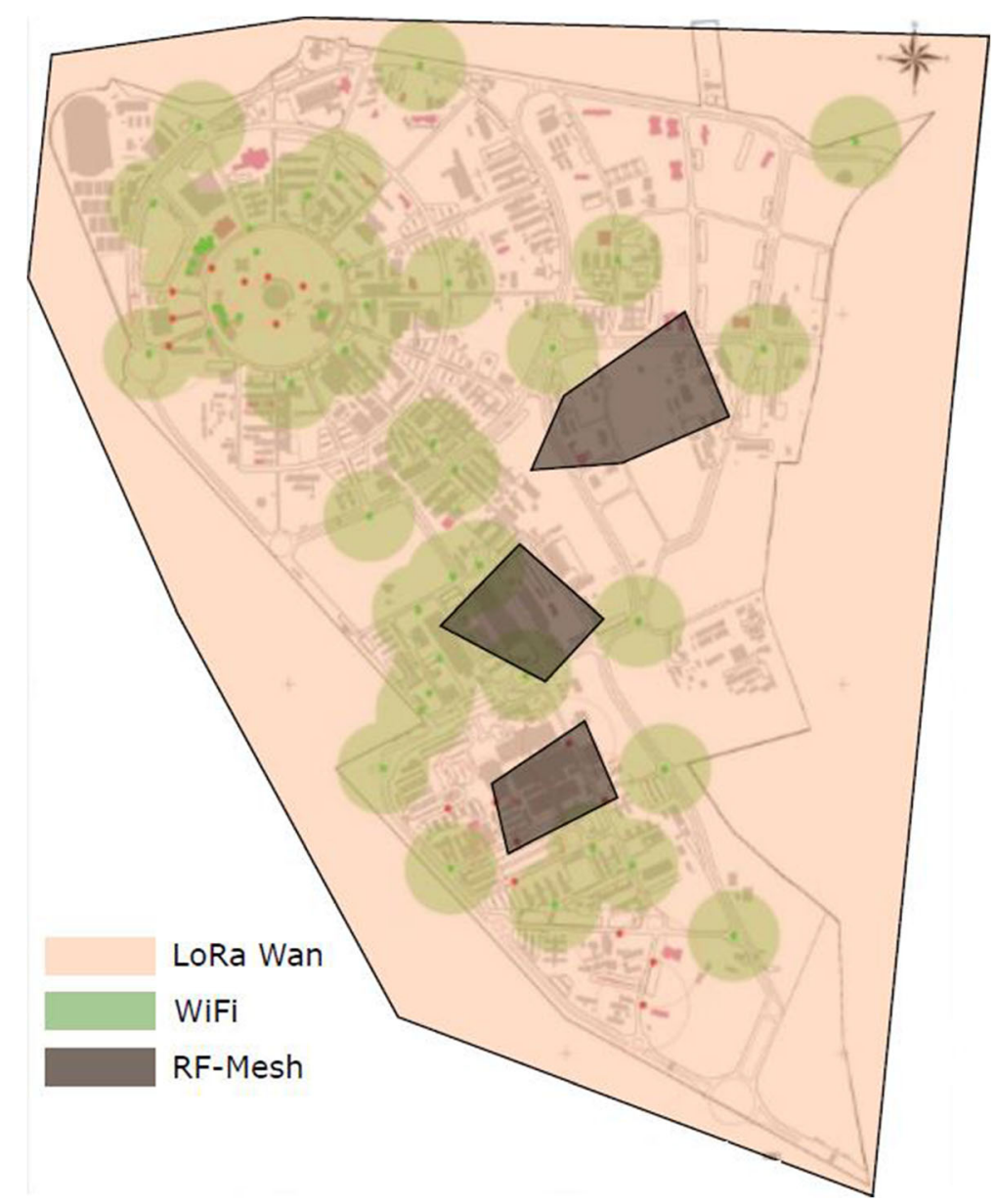

Fig. 3 Communication solutions for loT

\section{Partial results}

The envisioned project benefits cover four aspects: 1) Energy savings: based on the energy management system with continuous improvement and contractual revision;

2) Low emission policies: based on equipment specification, standardization and usage improvement; 3) Energy efficiency: based on building retrofit and building labeling; and 4) Renewable generation: based on the photovoltaic panels.

All sub-projects described in Fig. 1 are in progress in different accomplishment levels. The 300 electric energy meters are already installed, including all the transformers. Energy data is collected to be used in Smart Operation Center, as shown in Fig. 4.

The $534 \mathrm{kWp}$ installation of photovoltaic generation, distributed in several buildings, provides around $780 \mathrm{MWh} /$ year and a $1.13 \%$ energy reduction in annual energy consumption. In the future, the potential photovoltaic generation can achieve $16 \mathrm{MWp}$ generation, only considering the available rooftop areas.

Figure 5 shows the IoT system architecture. Different sensors and actuators are controlled by a centralized hub. The hub is a gateway that communicates with several devices and works as an abstract layer, isolating specific protocols and rules from different manufacturers or prototypes from the rest of the system. The web server is a cloud based solution to integrate different systems in order to execute energy efficiency 


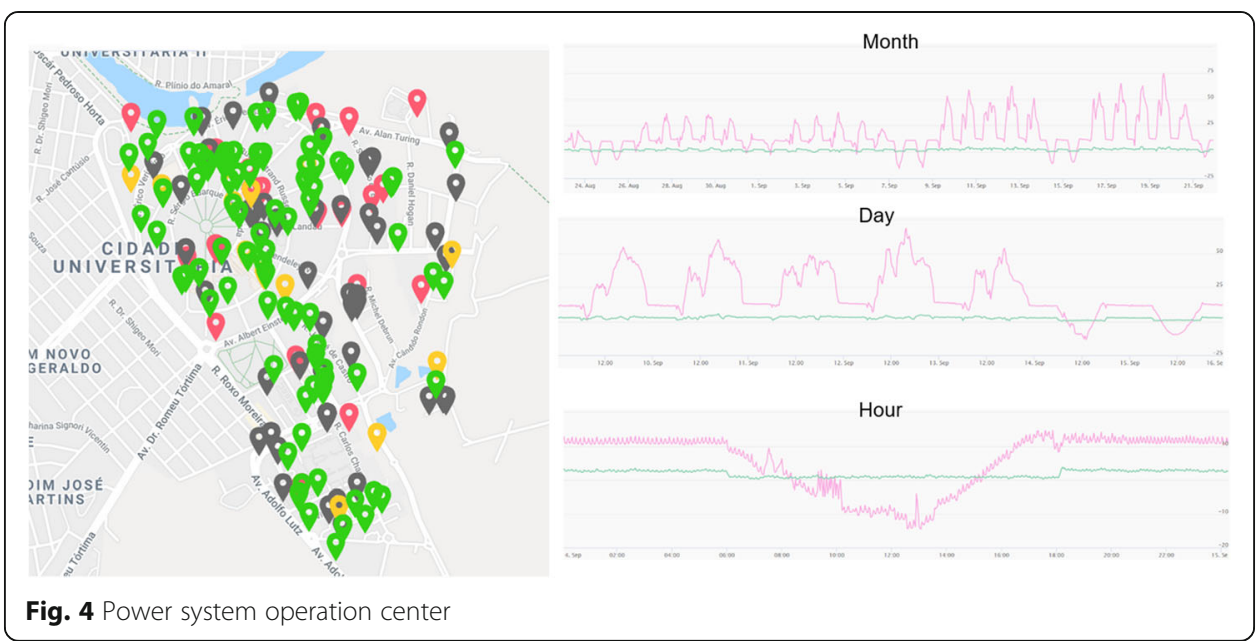

algorithms together with different model to achieve better management and control of the final solution. A user interface is available to provide visual reference and control points spread through the whole system.

The transport system is already in developing with real-time monitoring of the electricity distribution network and intelligent management and monitoring of the zeroenergy charging stations. A comprehensive monitoring of conventional and electric buses are being established.

\section{Conclusion}

The objective of this project is to obtain a gradual economy with electricity expenses. In order to achieve this, a software toolchain is proposed to enhance the management and integration of sustainable campus systems. This can only be achieved with the "digitization" of information, in which, through methodological analysis, information can be created for decision-making by University agents.

The project is being tested at the University of Campinas (UNICAMP), where three different communication networks were installed to allow real-time data acquisition using building IoT devices, such as temperature, humidity, luminosity, energy consumption, etc. The campus also invested in photovoltaic panels and energy efficient systems, such as new modern air conditioning units.

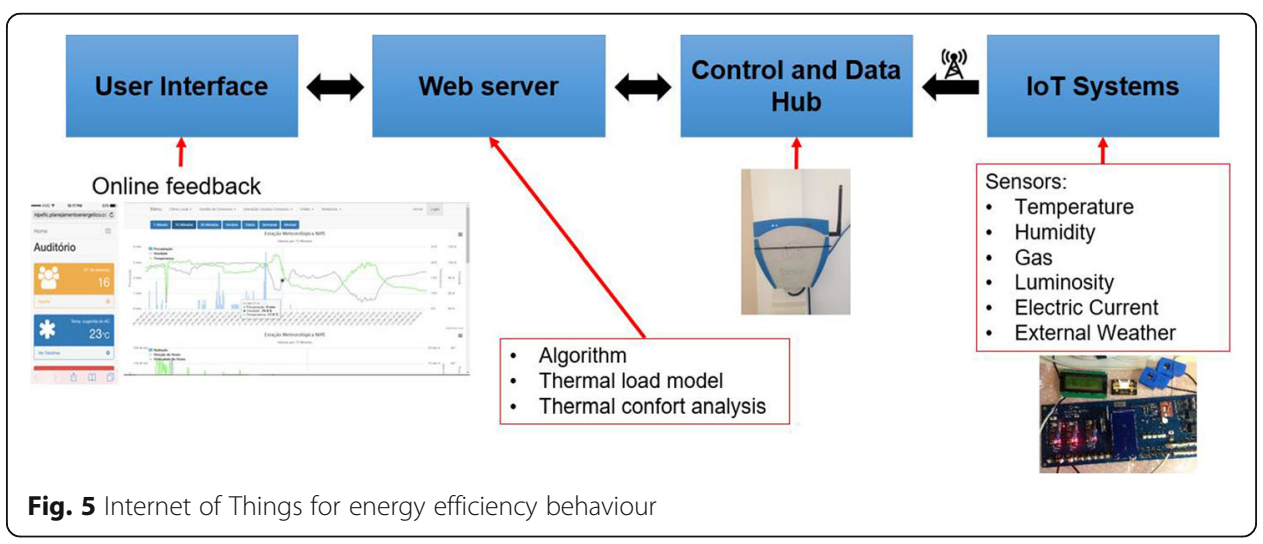


The project integrates energy efficiency with research and development in distributed generation with an innovative IoT-based DMS energy management tool. We expect to become a model of energy management and efficiency for other major universities in Brazil and Latin America.

\section{Abbreviations}

ANEEL: National electric energy agency; API: Application programming interface; CPFL: Local Brazilian utility distribution company; CPqD: Research and development center in telecommunications; DER: Distributed energy resources; DMS: Demand management system; EMS: Energy management system; FDW: Foreign data wrappers; GIS: Geographic information System; ICT: Information and communications technology; IOT: Internet of Things; ISCN-GULF: ISCN-GULF; LoRa: Low range wireless radio frequency technology; MAS: Multi-agent system; Postgres: PostgreSQL database; RES: Renewable energy sources; RDBMS: Relational database management system; MIT: Massachusetts institute of technology; UNICAMP: University of Campinas

\section{Acknowledgments}

Not applicable.

\section{About this supplement}

This article has been published as part of Energy Informatics Volume 4, Supplement 2 2021: Proceedings of the Energy Informatics.Academy Conference Asia 2021. The full contents of the supplement are available at https:// energyinformatics.springeropen.com/articles/supplements/volume-4-supplement-2.

\section{Authors' contributions}

L.C.P.S.: Investigation, supervision, funding acquisition; P.C.M. M., J.G.I.C., H.A.D.A., and A.Q.S.: Writing - review and editing. All authors read and approved the final manuscript.

\section{Funding}

This work is supported by the "The Sustainable Campus" project, funded by CPFL Energia under the scope of the R\&D (Research and Development) and PEE (Energy Efficiency Program) programs of ANEEL (National Electric Energy Agency), Brazil.

Availability of data and materials

Not applicable.

\section{Declarations}

Ethics approval and consent to participate

Not applicable.

\section{Consent for publication}

Not applicable.

\section{Competing interests}

The authors declare that they have no competing interests.

\section{Author details}

${ }^{1}$ University of Campinas, Zeferino Vaz Campus, Campinas, SP, Brazil. ${ }^{2}$ Center for Energy Informatics, University of Southern Denmark, Mærsk Mc-Kinney Møller Instituttet, Odense, Denmark.

Published: 24 September 2021

\section{References}

Aghemo C, Virgone J, Fracastoro GV, Pellegrino A, Blaso L, Savoyat J, Johannes K (2013) Management and monitoring of public buildings through ict based systems: control rules for energy saving with lighting and hvac services. Front Archit Res 2(2):147-161. https://doi.org/10.1016/j.foar.2012.11.001

ANEEL: Energy efficiency and mini generation in public higher education institutions. Technical report, ANEEL (2017). https:// goo.gl/AVYF5r. [Online; accessed 26-Feb-2021]

Bates O, Friday A (2017) Beyond data in the smart city: repurposing existing campus iot. IEEE Pervasive Computing 16(2):5460. https://doi.org/10.1109/MPRV.2017.30

Bracco S, Brignone M, Delfino F, Procopio R (2017) An energy management system for the Savona campus smart polygeneration microgrid. IEEE Syst J 11(3):1799-1809. https://doi.org/10.1109/JSYST.2015.2419273

CPQD: dojot Solucoes para IOT - Plataforma de Desenvolvimento para IOT (2017). https://dojot.com.br/. [Online; accessed 26Feb-2021]

Delzendeh E, Wu S, Lee A, Zhou Y (2017) The impact of occupants' behaviours on building energy analysis: a research review. Renew Sust Energ Rev 80:1061-1071. https://doi.org/10.1016/j.rser.2017.05.264

Facts\&Trends: Energy efficiency in buildings. Technical report, World Business Council for Sustainable Development (2008). https://www.wbcsd.org/Programs/Cities-and-Mobility/Resources/Business-realities-and-opportunities-Full-Report. [Online; accessed 15-Jun-2021] 
Ferber J, Gutknecht O, Michel F (2004) From agents to organizations: An organizational view of multi-agent systems. In: Giorgini P, Muller J, Odell J (eds) Agent-Oriented Software Engineering IV. Lecture Notes in Computer Science, vol 2935. Springer, pp 214-230. https://doi.org/10.1007/978-3-540-24620-6_15

Government, B.: Intended nationally determined contribution: Towards achieving the objective of the united nations framework convention on climate change. Technical report, FEDERATIVE REPUBLIC OF BRAZIL (2016). https://unfccc.int/ files/adaptation/application/pdf/all__parties_indc.pdf. [Online; accessed 15-Jun-2021]

Jennings NR, Wooldridge M (1995) Applying agent technology. Appl Artif Intell 9(4):357-369. https://doi.org/10.1080/0883951 9508945480 http://dx.doi.org/10.1080/08839519508945480. [Online; accessed 26-Feb-2021]

Polyzotis, N., Roy, S., Whang, S. E., and Zinkevich, M., Data Management Challenges in Production Machine Learning. In Proceedings of the 2017 ACM international conference on Management of Data (SIGMOD '17), 2017. Association for Computing Machinery, New York, NY, USA, 1723-1726. DOl:https://doi.org/https://doi.org/10.1145/3035918.3054782

Quan SJ, Economou A, Grasl T, Yang PP-J (2014) Computing energy performance of building density, shape and typology in urban context. Energy Procedia 61:1602-1605. https://doi.org/10.1016/j.egypro.2014.12.181 International Conference on Applied Energy, ICAE2014

Sun Y, Song H, Jara AJ, Bie R (2016) Internet of things and big data analytics for smart and connected communities. IEEE Access 4:766-773. https://doi.org/10.1109/ACCESS.2016.2529723

Wan J, Tang S, Li D, Wang S, Liu C, Abbas H, Vasilakos AV (2017) A manufacturing big data solution for active preventive maintenance. IEEE Trans Ind Inform 13(4):2039-2047. https://doi.org/10.1109/TII.2017.2670505

Wang S, Ouyang J, Li D, Liu C (2017) An integrated industrial ethernet solution for the implementation of smart factory. IEEE Access 5:25455-25462. https://doi.org/10.1109/ACCESS.2017.2770180

Yousefi F, Gholipour Y, Yan W (2017) A study of the impact of occupant behaviors on energy performance of building envelopes using occupants' data. Energy Buildings 148:182-198. https://doi.org/10.1016/j.enbuild.2017.04.085

Zhang D, Wan J, Liu Q, Guan X, Liang X (2012) A taxonomy of agent technologies for ubiquitous computing environments. KSII Trans Internet Inf Syst 6(2):547-565. https://doi.org/10.1109/TII.2017.2670505

\section{Publisher's Note}

Springer Nature remains neutral with regard to jurisdictional claims in published maps and institutional affiliations.

\section{Submit your manuscript to a SpringerOpen ${ }^{\circ}$ journal and benefit from:}

- Convenient online submission

- Rigorous peer review

- Open access: articles freely available online

- High visibility within the field

- Retaining the copyright to your article

Submit your next manuscript at $\boldsymbol{\nabla}$ springeropen.com 